\title{
Programmable organic light-emitting devices
}

\author{
C.-C. Wu, ${ }^{\text {a) }}$ C.-W. Chen, and Y.-T. Lin \\ Department of Electrical Engineering and Graduate Institute of Electro-Optical Engineering, \\ National Taiwan University, Taipei, Taiwan 10617, Republic of China \\ H.-L. Yu, J.-H. Hsu, and T.-Y. Luh \\ Department of Chemistry, National Taiwan University, Taipei, Taiwan 10617, Republic of China
}

(Received 10 April 2001; accepted for publication 6 September 2001)

\begin{abstract}
In this letter, we report a promising type of electrically programmable, i.e., reconfigurable, organic light-emitting devices (OLEDs) incorporating a thin carrier-blocking layer as the sacrificial fusing layer. In such devices, the carrier-blocking layer has a lower glass transition temperature than neighboring layers. By raising the internal temperature of the device above the transition temperature of the carrier-blocking layer with a large enough current, interdiffusion between organic layers could occur through such a layer. As a consequence, neighboring layers are fused and a new path for carrier transport is formed, bypassing the carrier-blocking property and altering the device characteristics. A device that emits blue light as fabricated but can be transformed into a green-emitting one is demonstrated. Such a type of device may be used for color pixels in OLED displays, user-programmable OLED applications, and nonvolatile memory devices. (C) 2001 American Institute of Physics. [DOI: 10.1063/1.1414305]
\end{abstract}

Organic light-emitting devices (OLEDs) based on either low-molecular-weight compounds or polymers have attracted worldwide interest due to their applications in efficient, low-voltage, large-area, and full-color displays. ${ }^{1,2}$ For most of the OLEDs reported to date, the device configurations, and consequently device characteristics, are determined on completion of fabrication, not reconfigurable afterward. Reconfigurable OLEDs, particularly electrically reconfigurable ones, may have some interesting applications due to their programmability. Devices that can be programed to emit different colors may be used for color pixels in OLED displays. Thus, only one type of device needs to be fabricated and the definition of color pixels can be performed by applying electrical programing pulses, simplifying display manufacturing. Such devices also make possible OLED applications that allow users to program colors or patterns for their own purposes. Futhermore, with irreversible reconfiguration, such devices may be used as programmable and nonvolatile memory devices, utilizing shifts of emission wavelengths or electrical characteristics to represent stored states. The closest matches to electrically programmable OLEDs are those with bias- or polarity-controlled emission colors. ${ }^{3-6}$ These devices, however, in general suffer from insufficient color contrast, limited brightness in some color, or poor efficiency. Futhermore, none of these previous devices have memory. In this letter, we report a type of electrically reconfigurable OLEDs, whose device configurations and characteristics can be programed electrically without necessarily losing efficiency or brightness. The transformation induced is irreversible and, therefore, nonvolatile.

The device structure and materials studied are shown

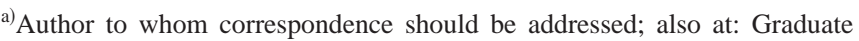
Institute of Electronic Engineering, National Taiwan University, Taipei, Taiwan 10617, Republic of China; electronic mail: chungwu@cc.ee.ntu.edu.tw
}

in Fig. 1. Bis-4,4'-[(diphenylmethylsilyl)viny 1]biphenyl (DPSVB) was synthesized from nickel-catalyzed silylolefination of the corresponding bisdithioacetal. ${ }^{7-9}$ DPSVB is able to form homogeneous films through vacuum evaporation and its thin film exhibits an absorption onset and fluorescence around 365 and $390 \mathrm{~nm}$, respectively. The device on the glass substrate has the typical structure of multiple organic layers sandwiched between the bottom indium-tinoxide (ITO) anode and the top $\mathrm{Mg}: \mathrm{Ag} / \mathrm{Ag}$ bilayer cathode. The stack of organic layers consists of a thin layer of conducting polymer polyethylene dioxythiophene/polystyrene sulphonate (PEDT/PSS, Bayer Corp.) as the hole-injection layer, ${ }^{10} \alpha$-naphthylphenylbiphenyl diamine ( $\alpha$-NPD) as the hole-transport layer, tris-(8-hydroxyquinoline) aluminum $\left(\mathrm{Alq}_{3}\right)$ as the electron-transport layer, ${ }^{1.8}$ and DPSVB inserted between $\alpha$-NPD and $\mathrm{Alq}_{3}$. The function of DPSVB will be described in the following paragraphs. All the compounds of low molecular weight were purified by sublimation before use in device fabrication. The PEDT/PSS layer was prepared by spin coating. $\alpha$-NPD, DPSVB, and $\mathrm{Alq}_{3}$ were deposited at a rate of $2-3 \AA / \mathrm{s}$ by thermal evaporation in a multiplesource vacuum chamber with a base pressure of $<10^{-6}$ Torr. The thicknesses of PEDT/PSS, $\alpha$-NPD, DPSVB, and $\mathrm{Alq}_{3}$ were $\sim 300,600,150$, and $300 \AA$, respectively.

In the current-voltage-brightness $(I-V-L)$ characteriza-

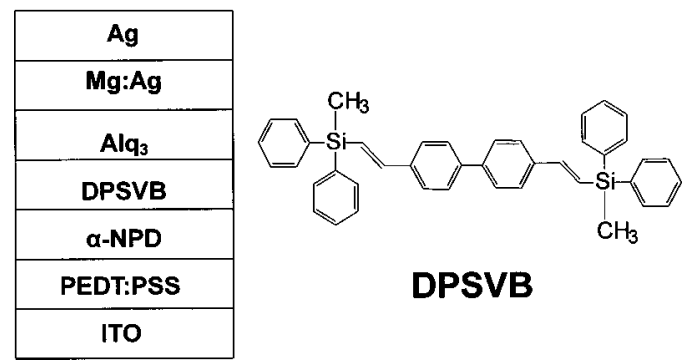

FIG. 1. Structures of the device and the compound. 

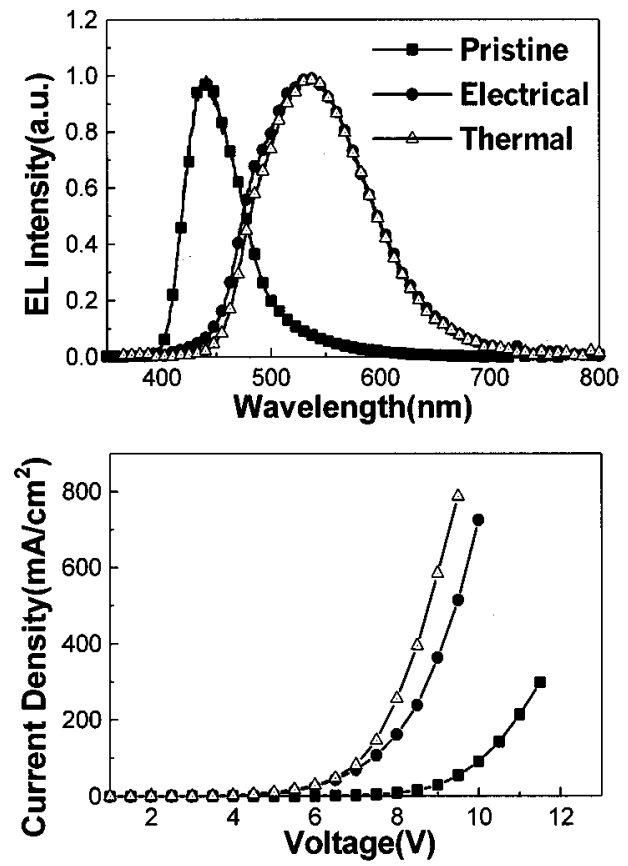

(b)

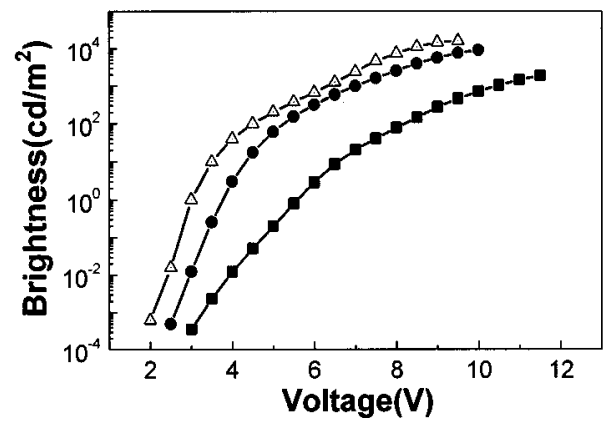

(c)

FIG. 2. (a) EL spectra, (b) $I-V$, and (c) $L-V$ characteristics of a pristine device, an electrically transformed device, and a thermally transformed device. Transformation conditions: $500 \mathrm{~mA} / \mathrm{cm}^{2}, 5 \mathrm{~s}$, or annealing at $60{ }^{\circ} \mathrm{C}, 3$ $\min$.

tion of the devices by continuously scanning bias voltage (e.g., $0.5 \mathrm{~V}$ step, $1 \mathrm{~s}$ hold time), it was repeatedly observed that the device initially emitting blue light irreversible transformed into a green-emitting one if the driving current exceeded $200-250 \mathrm{~mA} / \mathrm{cm}^{2}$. Further characterization revealed that the device could be fully transformed into a green one with a high current pulse (e.g., $500 \mathrm{~mA} / \mathrm{cm}^{2}, 5 \mathrm{~s}$ ). The electroluminescence (EL) spectra taken under much shorter pulse driving (tens of ms) for the original blue device and the transformed green device exhibited hardly any bias dependence. The phenomena observed here are, therefore, different from previously reported OLEDs with bias-controlled colors. $^{3-6}$ The spectral and representative $I-V-L$ characteristics of devices, before and after such a transformation, are shown in Fig. 2. The EL spectra of the original blue device and the transformed green device are identified as emission characteristics of $\alpha$-NPD and $\mathrm{Alq}_{3}$, respectively. It indicates that the carrier recombination in the original device occurs within the $\alpha$-NPD layer and that DPSVB actually functions as an effective hole-blocking and electron-transport layer. Nevertheless, stressing the device with a large enough current had caused some irreversible structural change, having the emission take place at $\mathrm{Alq}_{3}$ instead. The original blue device has an external quantum efficiency of $\sim 0.9 \%-1.0 \%$

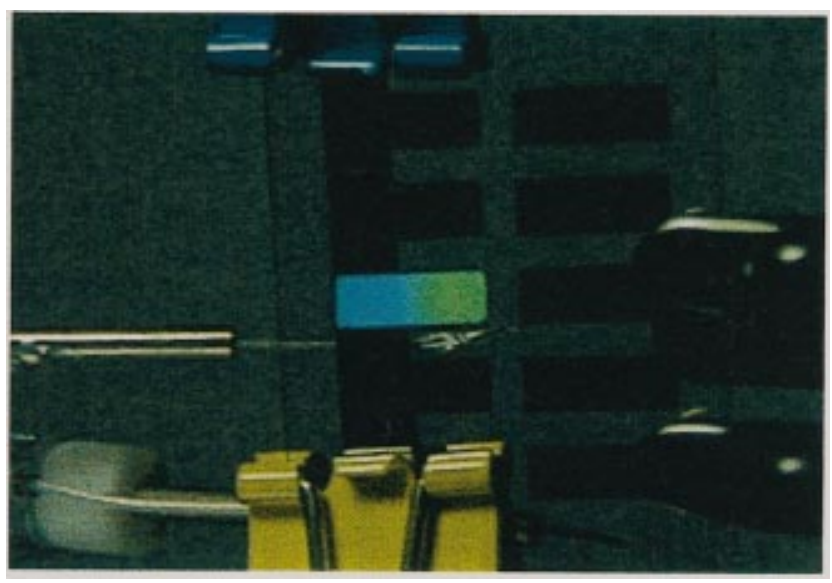

FIG. 3. (Color) Photograph of a device under the heat-sink experiment.

photon/electron and can be scanned to a brightness up to $\sim 1000 \mathrm{~cd} / \mathrm{m}^{2}$ before visible transformation takes place. The transformed green device, correspondingly, gives a quantum efficiency of $0.6 \%-0.7 \%$ and a brightness over $10,000 \mathrm{~cd} /$ $\mathrm{m}^{2}$. Compared to the original blue device, the $I-V-L$ characteristics of the transformed green device shift to lower voltages. The transformed device, therefore, is still a wellbehaved and functional device. All the above characteristics make the present device an electrically programmable one, whose emission color and electrical characteristics can be programed through a high-current pulse after device fabrication.

The changes induced by the applied current may be due to some electrochemical mechanism ${ }^{11}$ or due to some thermal effect caused by joule heat. ${ }^{12}$ To determine which is the dominant mechanism, we performed a heat-sink experiment, in which a portion of the cathode area of a device was in contact with a heat sink to keep it cooler than the remaining area while a current $\left(\sim 200 \mathrm{~mA} / \mathrm{cm}^{2}\right)$ was applied. It was found that the transformation of the contacted area was much retarded in comparison with the noncontacted area, as shown in Fig. 3. Since the current was initially uniformly distributed, such a test clearly suggests that the transformation is mainly of thermal origin. The usually reported thermal effects on the organic layers in OLEDs have been the recrystallization ${ }^{13}$ or the interdiffusion between organic layers, ${ }^{14,15}$ both depending on the considered temperatures relative to the glass transition temperatures $\left(\mathrm{T}_{\mathrm{g}}\right)$ of organic materials. $\mathrm{T}_{\mathrm{g}}$ of $\alpha$-NPD and $\mathrm{Alq}_{3}$ are $\sim 100$ and $\sim 170{ }^{\circ} \mathrm{C}$, respectively. ${ }^{13,15}$ The differential scanning calorimetry (DSC) of DPSVB shows a distinct glass transition around $30^{\circ} \mathrm{C}$. Hence, it was suspected that the lower $T_{g}$ of DPSVB is the origin of the structural change in the present device. For confirmation, we performed another set of thermal annealing experiments, in which the complete organic stack was annealed at various temperatures for $3 \mathrm{~min}$ prior to or after the cathode deposition. In both cases, annealing at $50-100{ }^{\circ} \mathrm{C}$ $\left(>\mathrm{T}_{\mathrm{g}}\right.$ of DPSVB, but still $<\mathrm{T}_{\mathrm{g}}$ of $\alpha$-NPD and $\left.\mathrm{Alq}_{3}\right)$ had readily made the devices green-emitting ones without further electrical stressing. The green devices transformed through thermal annealing have similar characteristics as those transformed through electrical stressing, as also shown in Fig. 2. All the above evidence suggests that electrical stressing 


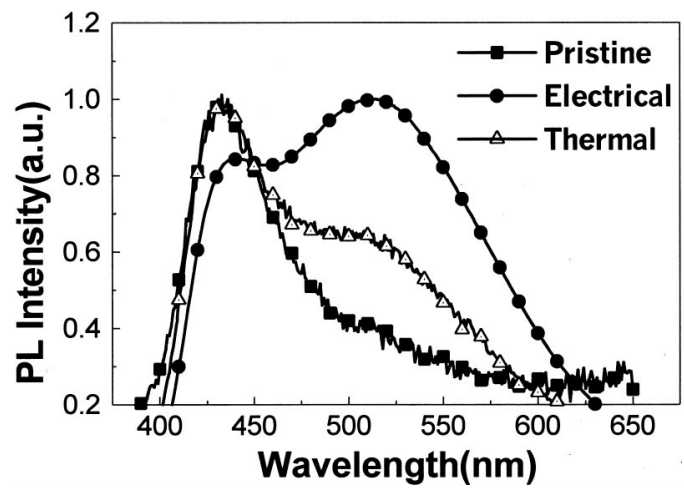

FIG. 4. PL spectra of a pristine device, an electrically transformed device, and a thermally transformed device. Transformation conditions: $500 \mathrm{~mA} /$ $\mathrm{cm}^{2}, 5 \mathrm{~s}$, or annealing at $60{ }^{\circ} \mathrm{C}, 3 \mathrm{~min}$.

caused similar thermal effects on the DPSVB layer as direct thermal annealing.

From the optical microscopy, even though substantial morphological changes were observed in annealing (50$\left.100^{\circ} \mathrm{C}\right)$ a thin DPSVB layer $(150 \AA)$ individually deposited on a substrate, the stack of organic layers subject to either thermal annealing or electrical stressing, however, still exhibited a homogeneous appearance and emission from the transformed devices was uniform. It is, therefore, less likely that the transformation of device characteristics was due to dramatic morphological change, such as formation of dense pinholes in DPSVB. Instead, investigation of resonant energy transfer between chromophores in the pristine device and in annealed or stressed ones revealed interdiffusion of chromophores through the DPSVB layer. Figure 4 shows the photoluminescence (PL) spectra collected from the ITO/glass side for the organic stacks in a pristine device, an electrically transformed device $\left(500 \mathrm{~mA} / \mathrm{cm}^{2}, 5 \mathrm{~s}\right)$, and a thermally transformed device $\left(60^{\circ} \mathrm{C}, 3 \mathrm{~min}\right)$. An excitation at $365 \mathrm{~nm}$ was adopted here because at this wavelength the optical densities of both DPSVB $(150 \AA)$ and $\mathrm{Alq}_{3}(300 \AA)$ are much smaller than that of $\alpha$-NPD (600 $)$ ). The PL spectrum of the pristine device shows a dominant $\alpha$-NPD emission, while those of both transformed devices exhibit substantial contribution from $\mathrm{Alq}_{3}$, clearly indicating energy transfer from $\alpha$-NPD to $\mathrm{Alq}_{3}$ in both fully transformed devices. Further PL studies using the excitation at $310 \mathrm{~nm}$ (for maximizing absorption in DPSVB and minimizing absorption in $\alpha$-NPD and $\mathrm{Alq}_{3}$ ) showed the increase of energy transfer from DPSVB to $\alpha$-NPD and $\mathrm{Alq}_{3}$ with the degree of annealing or stressing even before the energy transfer from $\alpha$-NPD to $\mathrm{Alq}_{3}$ was observed with the $365 \mathrm{~nm}$ pumping. These PL results suggest the interdiffusion actually starts at both DPSVB $/ \alpha$-NPD and DPSVB $/ \mathrm{Alq}_{3}$ interfaces and eventually leads to the substantial mixing of the initially separated $\alpha$-NPD and $\mathrm{Alq}_{3}$ layers in fully transformed devices. The mixing and bridging of $\alpha$-NPD and $\mathrm{Alq}_{3}$ through DPSVB then results in the formation of a new path for the carrier transport, bypassing the hole-blocking property of DPSVB and altering device characteristics. Such mixing and bridging may also explain the reduction of operation voltage in the transformed devices.
In the present device, owing to the rather low $\mathrm{T}_{\mathrm{g}}$ of the hole-blocking DPSVB layer, the blue operation of the original configuration can maintain only up to $200-250 \mathrm{~mA} / \mathrm{cm}^{2}$ under scanning operation. Under dc operation, the transformation is much more retarded by reducing the current below $10 \mathrm{~mA} / \mathrm{cm}^{2}$, but is still slightly detectable. Eventually, to make practical programmable devices, it is necessary to raise the transition temperatures of all compounds involved to ensure stable operation within the nominal temperature range. Correspondingly, higher programing currents may be needed, which in turn may impose requirements on the strength of all interfaces in devices. ${ }^{16}$ Currently, further work is toward the extension of the device operation range and reliability.

In summary, we report a promising type of electrically programmable or reconfigurable OLEDs incorporating a thin carrier-blocking layer. The carrier-blocking layer has lower $\mathrm{T}_{\mathrm{g}}$ than neighboring layers, so that by raising the internal temperature of the device above its $\mathrm{T}_{\mathrm{g}}$ with a large enough current, interdiffusion could occur through such a layer. As a consequence, neighboring layers are fused, bypassing the carrier-blocking property and altering the device configuration and characteristics. The concept disclosed in this work may be further generalized to make an OLED structure containing more than one carrier-blocking layer with different $\mathrm{T}_{\mathrm{g}}$ as sacrificial fusing layers, so that the device may be programed more than once. Such programmable OLEDs may have some interesting applications.

The authors would like to express gratitude to J. Lee of Junsun Technology Co. and H. R. Lien of Bayer Co. for assistance in the experiments. This work was supported by the National Science Council (Grant No. NSC 89-2215-E002-049) and Ministry of Education (Grant No. 89-N-FA012-4-2) of the Republic of China.

${ }^{1}$ C. W. Tang and S. A. VanSlyke, Appl. Phys. Lett. 51, 913 (1987).

${ }^{2}$ J. H. Burroughes, D. D. C. Bradley, A. R. Brown, R. N. Marks, K. Mackay, R. H. Friend, P. L. Burns, and A. B. Holmes, Nature (London) 347, 539 (1990).

${ }^{3}$ Y. Yang and Q. Pei, Appl. Phys. Lett. 68, 2708 (1996).

${ }^{4}$ M. Yoshida, A. Fujii, Y. Ohmori, and K. Yoshino, Appl. Phys. Lett. 69, 734 (1996).

${ }^{5}$ M. Berggren, O. Inganös, G. Gustafsson, J. C. Carlberg, J. Rasmusson, M. R. Anderson, T. Hjertberg, and O. Wennerström, Nature (London) 372, 444 (1994).

${ }^{6}$ M. Uchida, Y. Ohmori, T. Noguchi, T. Ohnishi, and K. Yoshino, Jpn. J. Appl. Phys., Part 2 32, L921 (1993).

${ }^{7}$ Z.-J. Ni, P.-F. Yang, D. K. P. Ng, Y.-L. Tzeng, and T.-Y. Luh, J. Am. Chem. Soc. 112, 9356 (1990).

${ }^{8}$ Z. Gao, C. S. Lee, I. Bello, S. T. Lee, R.-M. Chen, T.-Y. Luh, J. Shi, and C. W. Tang, Appl. Phys. Lett. 74, 865 (1999).

${ }^{9}$ T.-Y. Luh, S. Basu, and R.-M. Chen, Curr. Sci. 78, 1352 (2000).

${ }^{10}$ A. Elschner, F. Bruder, H. W. Heuer, F. Jonas, A. Karbach, S. Kirchmeyer, S. Thurm, and R. Wehrmann, Synth. Met. 111, 139 (2000).

${ }^{11}$ Y. Sato and H. Kanai, Mol. Cryst. Liq. Cryst. 253, 143 (1994).

${ }^{12}$ X. Zhou, J. He, L. S. Liao, M. Lu, X. M. Ding, X. Y. Hou, X. M. Zhang, X. Q. He, and S. T. Lee, Adv. Mater. 12, 265 (2000).

${ }^{13}$ E. M. Han, L.-M. Do, M. Fujihira, H. Inada, and Y. Shirota, J. Appl. Phys. 80, 3297 (1996)

${ }^{14}$ M. Fujihira, L.-M. Do, A. Koike, and E.-M. Han, Appl. Phys. Lett. 68, 1787 (1996)

${ }^{15}$ Z. Q. Gao, W. Y. Lai, T. C. Wong, C. S. Lee, I. Bello, and S. T. Lee, Appl. Phys. Lett. 74, 3269 (1999).

${ }^{16}$ V. Savvateev, A. Yakimov, and D. Davidov, Adv. Mater. 11, 519 (1999). 
Applied Physics Letters is copyrighted by the American Institute of Physics (AIP).

Redistribution of journal material is subject to the AIP online journal license and/or AIP copyright. For more information, see http:/ojps.aip.org/aplo/aplcr.jsp

Copyright of Applied Physics Letters is the property of American Institute of Physics and its content may not be copied or emailed to multiple sites or posted to a listserv without the copyright holder's express written permission. However, users may print, download, or email articles for individual use. 